\title{
Phytochemical Screening, HPTLC Finger Print and in vitro Antioxidant Activity of Bark Extracts of Lannea coromandelica (Houtt.) Merr.
}

\author{
Rajesh. R \\ Department of Pharmaceutical Analysis, Acharya \& BM Reddy College of Pharmacy, Soldevanahalli, Hessarghatta Main Road, \\ Bengaluru, Karnataka, INDIA.
}

\begin{abstract}
Background: Lannea coromandelica Merr (Houtt.) is used as a common medicinal plant among the tribal communities of Bangladesh has long been used in indigenous medicine for curing certain health disorders. Phytochemicals present in the bark are associated with their therapeutic capabilities. Objectives: The study was aimed to evaluate the HPTLC finger printing and in vitro antioxidant activity of methanol extract (MELC) and aqueous extract (AELC) of L. coromandelica bark extracts. Materials and Methods: The study consists of parameters which includes moisture content, ash values and ethanol and water soluble extractive values. Results: HPTLC finger print assessment will help to identify and monitor the drug effectiveness and ensure therapeutic efficacy. Antioxidant activity was measured using in vitro methods such as total phenolic content, total flavanoid content, 1,1 diphenyl 2 picryl hydrazyl (DPPH) radical scavenging potential, ferric ion reduction assay and phosphomolybdenum assay at different concentrations. MELC showed a high phenolic, flavanoid content, higher DPPH free radical scavenging, lower antioxidant ability of ferric ions and a phosphorous molybdenum assay compared to that of standard. Conclusion: The presence of natural phytoconstituents which are responsible for antioxidant activity in plant extracts. This may aid in further extensive studies for identifying and isolating compounds with potential therapeutic value in Lannea coromandelica (Houtt.) Merr.
\end{abstract}

Key words: Lannea coromandelica houtt, Phytochemistry, in vitro antioxidant activity, Physicochemical parameters, HPTLC.

\section{INTRODUCTION}

Natural products play a critical function in retaining human health by enhancing the quality of life. Due to the increasing awareness of natural products, demand for medicinal plants is rising, as it has fewer side effects compared to synthetic compounds, low price availability and cost-effectiveness. Bioactive compounds present in plants are alkaloids, flavonoids and terpenoids which are the rich source of antioxidant and have different structures in terms of functional group present in the structure contributes to antioxidant potential. ${ }^{1,2}$ Consequently, antioxidants and other phytocompounds present in these plants can prevent oxidative stress and its associated disorders. ${ }^{3,4}$
Various environmental stresses result in excessive ROS production resulting in progressive oxidative damage and eventually cell death. Scavenging or detoxification of excess ROS is accomplished by an efficient antioxidant mechanism consisting of both non-enzyme and enzyme antioxidants. ${ }^{5}$ Antioxidants are considered significant for maintaining health, modulating oxidative processes in the body. Despite the availability and regular use of many synthetic antioxidants, the protection and toxicity of these antioxidants are extremely important. ${ }^{6}$ Excess of free radicals and reactive oxygen species (ROS) in the current lifestyle will reduce the efficacy of antioxidants.
Submission Date: 30-07-2020; Revision Date: 24-09-2020; Accepted Date: 14-02-2021

DOI: 10.5530/ijper.55.2.88 Correspondence: Dr. Rajesh R Department of Pharmaceutical Analysis, Acharya \& BM Reddy College of Pharmacy, Soldevanahalli, Hessarghatta Main Road, Bengaluru-560 107, Karnataka, INDIA. Phone no: +91-80-28396011 Email id: rajeshr@acharya. ac.in

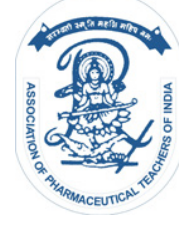

www.ijper.org 
Although ROS functions as second messengers, it can cause atherosclerosis, inflammation, neurodegenerative diseases, cataracts, cancer and aging, DNA mutation, protein oxidation and lipid peroxidation in both physiological as well as pathological pathways. ${ }^{7-12}$ The production of natural antioxidants by the human body eliminates the free radicals, prevents oxidative stress and associated diseases. Natural antioxidants play an significant role in health care. ${ }^{13}$ Phenolic acids, flavonoids, anthocyanins, tannins and carotenoids are the natural antioxidant sources of the plant. ${ }^{14,15}$

In a shorter time, TLC with better resolution varies from TLC only in particle size and the sorbents pore size is a major advancement. HPTLC is a valuable tool for accurate identification of herbal formulations, qualitative determination and quantitative determination of active ingredients of herbal extracts and synthetic drugs, standardization of herbal extracts and formulations, detection of adulteration, herbal extract stability studies and estimation of synthetic/natural drugs in the formulation. HPTLC can also provide chromatographic fingerprints that can be viewed and processed as electronic images and validation of analytical methods plays a crucial role in drug discovery, pharmaceutical development and production. ${ }^{16}$

The Lannea coromandelica (Houtt.) Merr. (Anacardiaceae) is a deciduous tropical tree widely distributed in India Bangladesh and other tropical countries. It has a wide scope around the world. ${ }^{17}$ The bark is effective in cuts, wounds, ulcers, ophthalmia, gout, ulcerative stomatitis, odontalgia, sprains, heart disease, diarrhoea and dysentery. The astringent bark is used as a lotion in impetiginous eruptions and severe ulcerations. ${ }^{18}$ The different parts of the plants have traditionally been used as therapeutic agents for various diseases. The bark of Lannea coromandelica was used by the tribal peoples of Bangladesh for the treatment of hepatitis, diabetes mellitus, ulcers, coronary heart disease and dysentery. ${ }^{19}$ Leaf juice has been taken orally to alleviate ulcers and pain, while fruit sap has been used to treat cold and cough. ${ }^{20,21}$ The bark of $L$. coromandelica was used to treat gout, dyspepsia, dysentery, skin eruption, ulcers and toothache. ${ }^{22,23}$ Researchers performed experimental studies focused on these traditional applications of Lannea coromandelica against various illnesses. Barks should have anti-inflammatory, hypotensive, antihyperglycaemic, antimicrobial, antimicrobial, analgesic and antioxidant effects. ${ }^{24-32}$ The aqueous extract of $L$. coromandelica antagonizes the glucagon receptor and has the ability to minimize the output of glucagon-mediated liver glucose and antinociceptive activity. 33,34
Quarcetin, (2S,3S,4R,10E)-2-[2'R)-2'-hdroxytetracosanoyl amino]-10-octadecene-1,3,4-triol, aralia cerebroside, 5,5'-dibuthoxy-2,2'-bifuran, $\beta$-sitostryl-3 $\beta$-glucopyranoside-6'-O-palmitate, $\beta$-sitosterol palmitate, myricadiol, protocatechuic acid, p-hydroxy benzoic acid ethyl ester, isovanillin, trans-cinnamic acid, palmitic acid and steric acid were isolated from the barks of Lannea coromandelica. ${ }^{35} \mathrm{HPLC}$ revealed the presence of gallicacid, (-) epigallocatechin-3- gallate, catechin, chlorogenic acid and caffeic acid in L. coromandelica bark extract. ${ }^{36}$ Bioassay guided fractionation and chemical characterization of Lannea extracts by MALDI-TOF-MS revealed that the active constituents were angular type of polyflavanoid tannins and exhibit zoosporicidal activity. ${ }^{37}$

In consideration of the traditional use of this drug, antioxidant activity was predicted in preliminary phytochemical studies. Therefore, the purpose of the study is to qualitatively and quantitatively evaluate the existence of different phytochemicals in Lannea coromandelica using the HPLTC technique and to investigate the in vitro antioxidant capacity of extracts of Lannea coromandelica bark.

\section{MATERIALS AND METHODS}

\section{Collection and authentication of plant material}

The L. coromandelica bark was collected from the southern region of Tamil Nadu, India. Plants were identified and certified with the help of Dr. V. Chelladurai, Research Officer- Botany, C.C.R.A.S. Govt of India, Tirunelveli, Tamil Nadu and a voucher specimen is retained in the department for future reference.

\section{Preparation of the plant extracts}

Weighing accurately about $500 \mathrm{~g}$ of bark of $L$. coromandelica were dried and milled into coarse powder and extracted for 7 days by increasing the polarity of organic solvents such as petroleum ether, chloroform, ethyl acetate, methanol by Soxhlet extractor and water (AELC) by maceration. After each extraction, the marc was collected and dried in the air, then repackaged in the apparatus. The extracts in the rotator evaporator were filtered and concentrated dried and stored in the desiccators under reduced pressure.

\section{Physico-chemical parameters}

Various physicochemical parameters were studied, such as total ash, insoluble acid ash, water-soluble ash, alcohol-soluble extractive value, water-soluble extractive value, foreign organic matter and loss on drying. ${ }^{38}$ 


\section{Preliminary phytochemical screening}

Phytochemical screening was performed to identify alkaloids, tannins, flavanoids and terpenoids. ${ }^{39,40}$

HPTLC profile, Development of chromatogram, scanning and detection of spots

It requires standardized manufacturing processes and adequate analytical tools to lay down the required framework for quality control in herbals. Highperformance thin-layer chromatography (HPTLC) is widely used separation techniques to establish fingerprints of reference for herbs. HPTLC fingerprint profile of MELC was executed. ${ }^{41,42}$ The sample solutions have been prepared and configured for fingerprinting of high quality. Approximately $5 \mathrm{mg} / \mathrm{ml}$ of MELC concentration in the respective HPLC grade solvents was made and filtered by Whatman filter paper No. 1. Prewashing for HPTLC plate by methanol and then dried. MELC was applied by Camag (Muttenz, Switzerland) Linomat $\mathrm{V}$ automated spray-on band applicator with a band length of $6 \mathrm{~mm}$ and $10 \mathrm{~s} \mu \mathrm{l}-1$ application rate of $100.00-\mu l$ (Hamilton) syringe. The band width was $6 \mathrm{~mm}$, the plate edge distance was 10 $\mathrm{mm}$ and the plate bottom distance was $10 \mathrm{~mm}$. Toluene: ethyl acetate: methanol $(60: 30: 10)$ was the mobile phase used for development. Mobile phase chamber saturation was performed for $20 \mathrm{~m}$ in twin trough glass chamber at room temperature $\left(30.5^{\circ} \mathrm{C}\right)$. The mobile phase was evaporated from the plate by using an air-dryer after development. The air-dried plate was examined for various secondary metabolites at $254 \mathrm{~nm}, 366 \mathrm{~nm}$ and visible light spectrum after $10 \mathrm{~m}$ of spraying with 10 percent $\mathrm{v} / \mathrm{v}$ vanillin sulphuric acid incubated at $110^{\circ} \mathrm{C}$.

Deuterium lamp and tungsten lamp have been used in absorbance mode for densitometric scanning at $254 \mathrm{~nm}$, $375 \mathrm{~nm}$ and $550 \mathrm{~nm}$.

\section{Determination of antioxidant activity Estimation of total phenolic content (TPC)}

Total phenolic content was evaluated using a slightly modified Folin-Ciocalteu reagent method. ${ }^{43}$ The FolinCiocalteu method is an electron transfer-based assay and provides reducing capacity expressed as phenolic content. Specified extracts $(200 \mu \mathrm{l})$ concentration was combined with Folin-Ciocalteu concentration and incubated for $10 \mathrm{~min}$. At $37^{\circ} \mathrm{C}$ for $90 \mathrm{~m}$, the reaction mixture was added $1.25 \mathrm{ml}$ of aqueous sodium carbonate and $1 \mathrm{ml}$ of distilled water and the absorbance measured at $760 \mathrm{~nm}$ of spectrophotometric and distilled water was used as blank. The standard gallic acid was used and expressed as $\mathrm{mg} /$ gallic acid (GAE) equivalent. All experiments were carried out in triplicate for precision and values were expressed as $\mathrm{mg}$ gallic acid equivalent (GAE)/g of the sample

\section{Total flavonoid content (TFC)}

Total flavanoid content was determined with slight modification by colorimetric assay of aluminium chloride. ${ }^{44}$ A volumetric flask ( $10 \mathrm{ml}$ volume) was added with $1 \mathrm{ml}$ of test sample and $4 \mathrm{ml}$ water. Add $0.3 \mathrm{ml}$ of $5 \%$ sodium nitrite and $0.3 \mathrm{ml}$ of $10 \%$ aluminum chloride after $5 \mathrm{~min}$. After $6 \mathrm{~m}$ of room temperature incubation, $1 \mathrm{ml}$ of $1 \mathrm{M}$ sodium hydroxide was added to the reaction mixture. $10 \mathrm{ml}$ of distilled water have been added to make the final volume. The sample absorbance was measured against the blank at $510 \mathrm{~nm}$ using UV spectrophotometer. All experiments were repeated three times for precision, total flavonoid content in terms of Quercetin equivalent (QE)/g of the sample.

\section{Free radical scavenging activity (DPPH)}

The method described by Brand-Williams was used to evaluate DPPH-free radical scavenging activities with minor modifications for the study of MELC and AELC antioxidant potential. ${ }^{45} \mathrm{DPPH}$-free radical scavenging activity was performed at a specified concentration of 100-500 $\mu \mathrm{l}$ of MELC and AELC dissolved in ethanol. DPPH $(0.004 \%)$ was prepared by dissolving in ethanol and added separately $1 \mathrm{ml}$ of the above solution to MELC, AELC and standard ascorbic acid. The above mixture was incubated for $30 \mathrm{~m}$ in the dark and the absorbance was measured spectrophotometrically at 517 $\mathrm{nm}$. The degree of color change from purple to yellow shows the MELC and AELC free radical scavenging efficiency. Lower absorption of the reaction indicated higher free radical scavenging activity.

DPPH scavenging activity $(\%)=\frac{\text { Ac-At }}{\text { Ac }} \times 100$

Ac is the control absorbance ( $1 \mathrm{ml}$ of DPPH solution in $1 \mathrm{ml}$ of ethanol)At is the test absorbance

Then, curves were created by plotting concentration in $\mu \mathrm{g} / \mathrm{ml}$ Vs percentage inhibition. The equation of this curve was used to calculate the $\mathrm{IC}_{50}$ corresponding to concentration of the drug that reduced the DPPH free radical scavenging to $50 \%$.

\section{Ferric ion reducing antioxidant power assay (FRAP)}

Ferric ion reduction ability of antioxidant power assay was performed as described by Benzie and Strain with minor modification method. ${ }^{46}$ The antioxidant activity of MELC and AELC was obtained by dissolving the different concentrations $(100 \mu \mathrm{l}$ to $500 \mu \mathrm{l})$ with a 2.5 $\mathrm{ml}$ of $0.2 \mathrm{mM}$ phosphate buffer (pH 7.4) and $2.5 \mathrm{ml}$ of 
potassium ferricyanide $(1 \% \mathrm{w} / \mathrm{v})$ incubated at $50^{\circ} \mathrm{C}$ for $20 \mathrm{~min}$. Add $2.5 \mathrm{ml}$ of trichloroacetic acid $(10 \% \mathrm{w} /$ v) and centrifuge for $10 \mathrm{~min}$ at $3000 \mathrm{rpm}$. To $2.5 \mathrm{ml}$ of the upper layer, add $2.5 \mathrm{ml}$ of distilled water and $0.5 \mathrm{ml}$ of ferrous chloride $(0.1 \% \mathrm{w} / \mathrm{v})$ and absorbance was measured by spectrophotometer at $700 \mathrm{~nm}$ against the standard ascorbic acid. Higher ferric ion reducing ability indicated by higher absorbance values of the reaction mixture.

\section{Phosphomolybdenum assay}

The total antioxidant capacity assay based on the reduction of $\mathrm{Mo}(\mathrm{VI})$ to $\mathrm{Mo}(\mathrm{V})$ by the sample analyte and the subsequent formation of a green phosphate $\mathrm{Mo}(\mathrm{V})$ complex at acidic $\mathrm{pH}$ is a spectroscopic method for the quantitative determination of antioxidant capacity through the formation of the phosphomolybdenum complex. Phosphomolybdenum (PM) assays were performed to determine total antioxidant activity according to Prieto et al. ${ }^{47}$ In each tube, MELC and AELC were added to $3 \mathrm{ml}$ of distilled water and $1 \mathrm{ml}$ of molybdate reagent at concentrations of $100 \mu \mathrm{l}$ and 500 $\mu$ l. Incubate for $90 \mathrm{~m}$ at $95^{\circ} \mathrm{C}$. Then they are maintained for 20 to $30 \mathrm{~m}$ at room temperature and the absorbance was spectrophotometrically measured against the standard ascorbic acid at $695 \mathrm{~nm}$.

\section{RESULTS}

\section{Phytochemical analysis}

Phytochemical analysis of petroleum ether, chloroform, ethyl acetate, methanol and aqueous extracts shows the presence of phytoconstituents such as alkaloids, flavanoids, phenol and saponins in EALC, MELC and AELC. Sterols are found to contain in petroleum ether and methanol extracts. Tannins are found to contain in methanol and aqueous extracts. In all the extracts, volatile oil was absent. The results of physicochemical parameters of $L$. coromandelica bark were summarized in Table 1.

\section{DISCUSSION}

Plants are the key source of bioactive compounds for the development of new chemotherapeutic agents. Phytochemical screening and physicochemical parameters were carried out to assess the quantity of soluble constituents and the quality and purity of a crude drug. Preliminary phytochemical analysis of the extracts shows alkaloids, flavanoids, phenol, tannins, sterols and saponins. Preliminary phytochemical studies provide researchers a broad idea for their further research. The total flavanoid content of in MELC and AELC was completely synchronous with that of the total phenolic content. It has been successfully demonstrated that samples with a high phenolic content also contain large amounts of flavonoids as Table 2. The rich-flavonoid crude drug can be a good source of antioxidants helping to increase the overall antioxidant potential of an organism and prevent lipid peroxidation. ${ }^{48}$

The physico chemical parameters for a plant are almost constant, so they help to set crude drug standards. These parameters are crucial for detecting adulteration or improper drug handling. To determine the purity and quality of drugs, assessing total ash is essential. There are three common methods for determining ash value, such as total ash, acid-insoluble ash and water-soluble ash. Ash value is the residue that remains after the incineration of plant material and is useful in assessing sample quality and purity, as well as providing important qualitative standards. Total ash content analysis is actually burning away organic matter, leaving inorganic minerals behind. This helps to evaluate the quantity and type of minerals in the drug that are useful in determining the physicochemical properties of the drug. Total ash containing both physiological and non-physiological ash typically consists of carbonates, phosphates, silicates and silica. A high ash value means contamination, substitution, adulteration or carelessness occurs, when the crude drug is being prepared for commercialization as shown in Table 1a. Extractive values are performed to assess the identity of the extractable polar or non-polar compounds in the drug. Loss on drying was performed on the drug to determine the moisture and should be excluded from the product absolutely. Microbial growth is possible if the crude drug is stored for a very long period of time and its stability is directly related to the moisture content of the crude drug. The lower the amount of the moisture, the greater the stability of the drug and the lower the risk of microbial growth as depicted in Table $1 \mathrm{~b}$.

\begin{tabular}{|c|c|}
\hline \multicolumn{2}{|c|}{ Table 1a: Physicochemical parameter. } \\
\hline Type of ash content & Ash values \\
\hline Total ash $(\% \mathrm{w} / \mathrm{w})$ & 4.9052 \\
\hline Acid Insoluble $(\% \mathrm{w} / \mathrm{w})$ & 1.2847 \\
\hline Water soluble ash $(\% \mathrm{w} / \mathrm{w})$ & 2.1437 \\
\hline \multicolumn{2}{|c|}{ Table 1b: Extractive values } \\
\hline Type of extractive values & Extractive values (\%w/w) \\
\hline Alcohol soluble extractives & 2.6552 \\
\hline Water soluble extractives & 4.3943 \\
\hline Foreign organic matter & 0.76 \\
\hline Moisture content & 4.36 \\
\hline
\end{tabular}

Results $(n=3$, Mean \pm SD) 
MELC had the best possible results in Toluene: ethyl acetate: methanol (60: 40:10) and solvent system. The plates were scanned and visualized in absorbance mode at both $254 \mathrm{~nm}, 375 \mathrm{~nm}, 550 \mathrm{~nm}$ and visible light range after spraying with 10 percent $\mathrm{v} / \mathrm{v}$ vanillin sulphuric acid reagent. The images from the HPTLC Figure 1 specify that all phytoconstituents were clearly separated without any tailings or diffusiveness. The results of HPTLC finger print scanned for MELC scanned at $254 \mathrm{~nm}$ revealed the presence of eight phytoconstituents. The $\mathbf{R}_{f}$ values were from 0.13 to 1.00 . MELC scanned at $375 \mathrm{~nm}$ and $550 \mathrm{~nm}$ revealed the presence of nine phytoconstituents (Table 3). The $\mathrm{R}_{f}$ values were from 0.09 to 0.94 and 0.16 to 0.94 respectively. From Table 3 and chromatogram as shown in Figure 2, of the nine components, $\mathrm{R}_{f}$ values $0.13,0.30,0.45$ was found predominantly higher as the percentage area is $30.32 \%, 15.43 \%$ and $19.43 \%$ respectively out of eight components. From Table 3 and chromatogram as shown in Figure 3, of the nine components, the component has $\mathrm{R}_{f}$ values $0.09,0.23$, 0.66, 0.49 was found to be more like $33.56 \%, 18.96 \%$, $15.55 \%$ respectively. From Table 3 and chromatogram as shown in Figure 4, of the nine components, the component has $\mathrm{R}_{f}$ values of $0.16,0.78$ were found to be more like $46.14 \%$ and $14.91 \%$ respectively. The proposed HPTLC method has been found to be more suitable for the calculating the number of constituents and also used in routine research as a rapid analytical tool to detect losses or variations in plant crude extract phytoconstituents. The HPTLC fingerprints developed will be useful in the manufacturer's quality control and standardization of herbal drugs and will also be useful in differentiating species from adulterants in the pharmaceutical industry and systematic plant studies.

\begin{tabular}{|c|c|}
\hline \multicolumn{2}{|c|}{ Table 2: Total phenol content (TPC). } \\
\hline Extracts & Total phenol content (mg GAE/ g sample) \\
\hline EALC & $11.42 \pm 0.45$ \\
\hline MELC & $54.72 \pm 0.21$ \\
\hline AELC & $45.51 \pm 0.25$ \\
\hline
\end{tabular}

Results $(n=3$, Mean \pm SD)
In MELC, the total phenolic content was higher than in EALC and AELC as shown in Table 2. Phenolic compounds are responsible for their function as antioxidants and also known for their redox properties in free radical absorption and neutralization; singlet and triplet oxygen quenching or peroxide decomposition. ${ }^{49}$ In MELC the total flavanoid content was higher than in EALC and AELC as shown in Table 4.

The DPPH assay was widely used as a simple, reliable and reproducible parameter to check the general in vitro antioxidant activity of pure compounds and plant extracts. ${ }^{50}$ Various concentrations of MELC and AELC were screened for free radical DPPH scavenging assay.
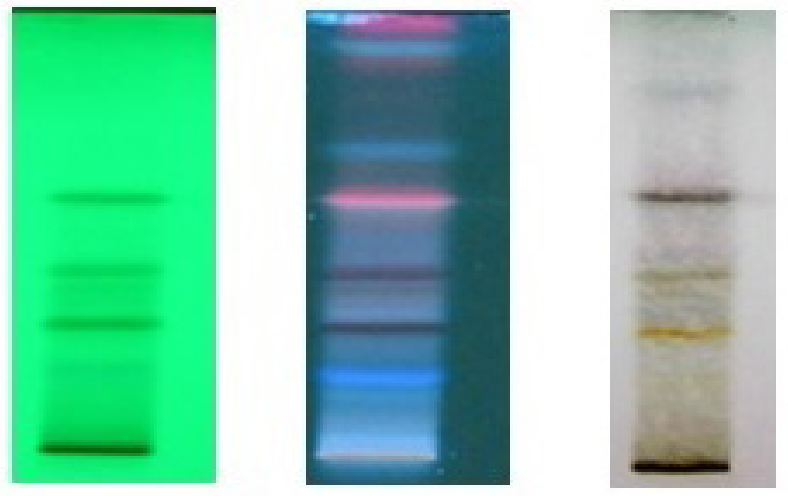

Figure 1: HPTLC fingerprint profile of MELC at $254 \mathrm{~nm}, 366$ $\mathrm{nm}$ and visible for secondary metabolites.

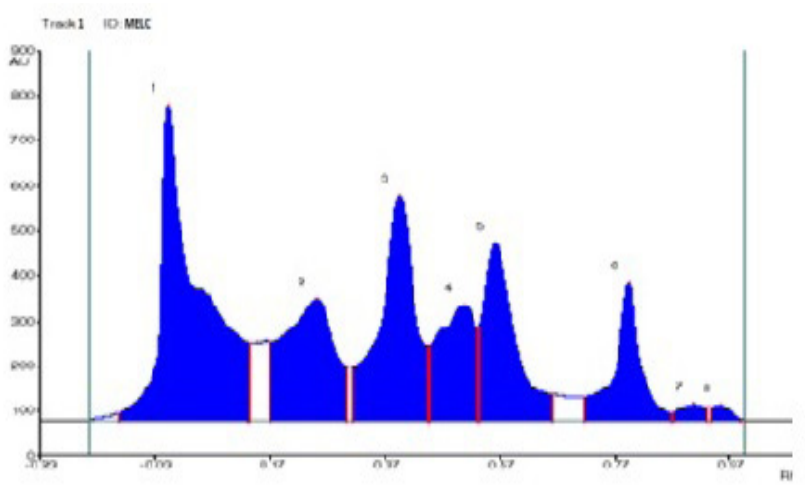

Figure 2: HPTLC profile of MELC scanned at $254 \mathrm{~nm}$.

\begin{tabular}{|c|c|c|c|c|}
\hline Extracts & Mobile phase & $\begin{array}{l}\text { No. of } \\
\text { Peaks }\end{array}$ & $\mathrm{R}_{f}$ Value & Percentage area $(\%)$ \\
\hline MELC at $254 \mathrm{~nm}$ & \multirow{3}{*}{$\begin{array}{l}\text { Toluene : } \\
\text { Ethyl acetate : } \\
\text { Methanol } \\
(60: 30: 10)\end{array}$} & 08 & $\begin{array}{l}0.13,0.30,0.45,0.53,0.66 \\
0.87,0.94,1.00\end{array}$ & $\begin{array}{l}30.32,15.43,19.43,10.54,13.91,8.70 \\
1.02,0.66\end{array}$ \\
\hline MELC at $375 \mathrm{~nm}$ & & 09 & $\begin{array}{l}0.09,0.23,0.29,0.35 \\
0.49,0.57,0.63,0.77,0.94\end{array}$ & $\begin{array}{l}\text { 33.56,18.96,5.71, 6.63,15.55,4.33, } \\
2.60,10.62,2.05\end{array}$ \\
\hline MELC at $550 \mathrm{~nm}$ & & 09 & $\begin{array}{l}0.16,0.22,0.30,0.41 \\
0.48,0.56,0.61,0.78,0.94\end{array}$ & $\begin{array}{l}46.14,9.27,8.08,4.72 \\
4.54,3.56,3.05,14.91,5.74\end{array}$ \\
\hline
\end{tabular}


Results indicated that MELC and AELC were capable of inhibiting DPPH-free radicals. As the extract concentration increased from 100 to $500 \mu \mathrm{g} / \mathrm{ml}$, it was found that DPPH activity increased. Inhibitory action of was compared with standard ascorbic acid. MELC antioxidant activity was higher than AELC as shown in Figure 5. Iron is essential for transporting oxygen, breathing and many enzyme functions. ${ }^{51}$

The presence of antioxidants in MELC and AELC will lead to the donation of an electron to reduce $\mathrm{Fe}^{3+}$ ferri cyanide to $\mathrm{Fe}^{2+}$ ferrocyanide. Together with standard ascorbic acid, FRAP assay was carried out in MELC and AELC. It was observed from the analysis that MELC displayed higher ferric ion diminishing antioxidant potential than AELC compared to standard ascorbic

\begin{tabular}{|c|c|}
\hline \multicolumn{2}{|c|}{ Table 4: Total flavanoid content (TFC). } \\
\hline Extracts & $\begin{array}{c}\text { Total flavanoid content (mg quarcetin/ g } \\
\text { sample) }\end{array}$ \\
\hline EALC & $4.42 \pm 0.45$ \\
\hline MELC & $19.72 \pm 0.21$ \\
\hline AELC & $17.51 \pm 0.25$ \\
\hline
\end{tabular}

Results $(n=3$, Mean \pm SD)

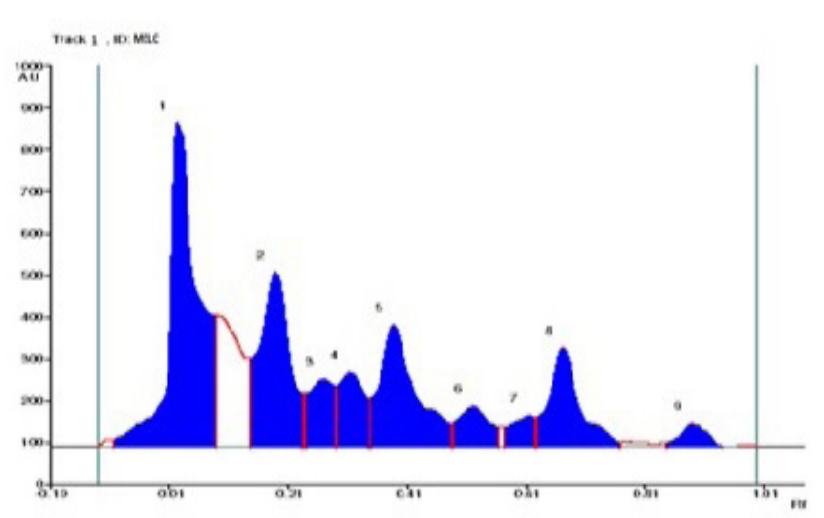

Figure 3: HPTLC profile of MELC scanned at $375 \mathrm{~nm}$.

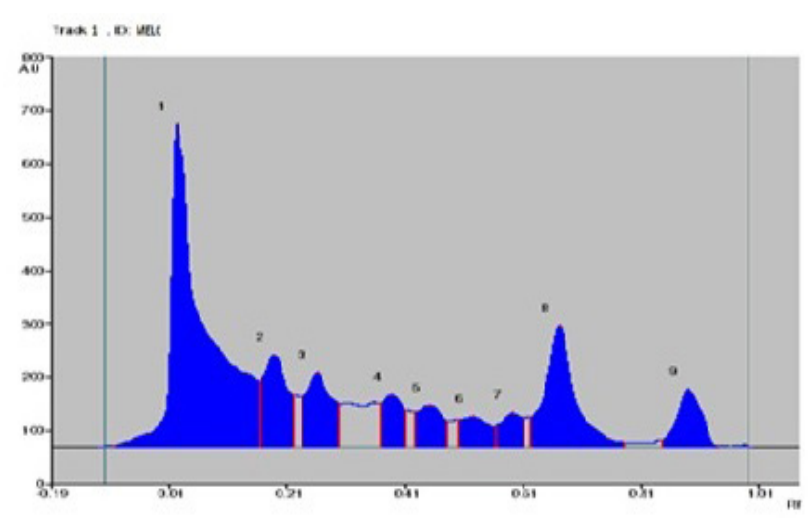

Figure 4: HPTLC profile of MELC scanned at $550 \mathrm{~nm}$. acid as Figure 6. The metal chelating ability of MELC was evaluated by the formation of a ferrous ion ferrozine complex and the reducing power of MELC increased in a concentration-dependent manner due to its electron donating ability of secondary metabolites. ${ }^{52}$ It involves in thermally generating auto-oxidation during prolonged incubation period at higher temperature. It will gives a direct estimation of reducing capacity of antioxidant. Without induction of free metal ions, it forms a green phosphomolybdenum complex. Phospho molybdenum assay was performed with MELC and AELC along with standard ascorbic acid. Compared to standard ascorbic acid, MELC showed the highest activity than AELC as shown in Figure 7. Due to their phenolic constituents, some plants exhibit antioxidant activity. A broad class of low molecular weight, secondary metabolites commonly found in plants are flavanoids. The beneficial effects of flavanoids are attributable to their antioxidant and chelating ability..$^{53}$ Our results on Lannea coromandelica bark extracts are in accordance with the Tekesh kumar etal reports. ${ }^{54}$ Imminent antioxidant properties of various leaf extracts of Lannea coromandelica have been

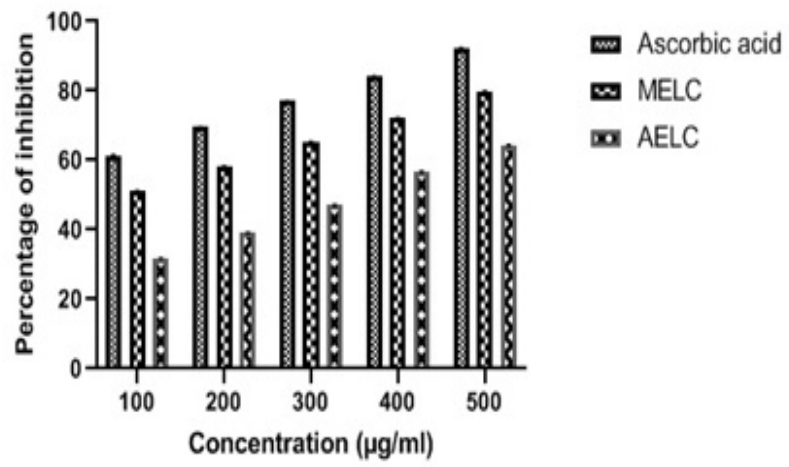

Figure 5: Free radical scavenging (DPPH) of MELC and AELC. Results expressed as the mean \pm standard deviation $(n=3)$.

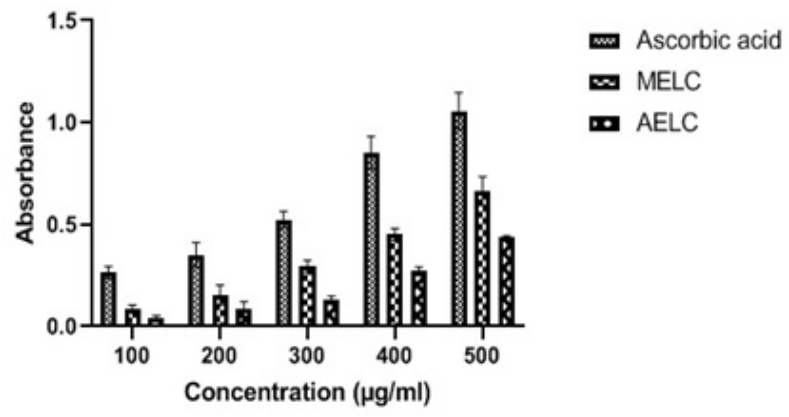

Figure 6: Ferric ion reducing antioxidant power assay (FRAP) of MELC and AELC compared to that of standard ascorbic acid. Each value is expressed as mean \pm standard deviation $(n=3)$. 


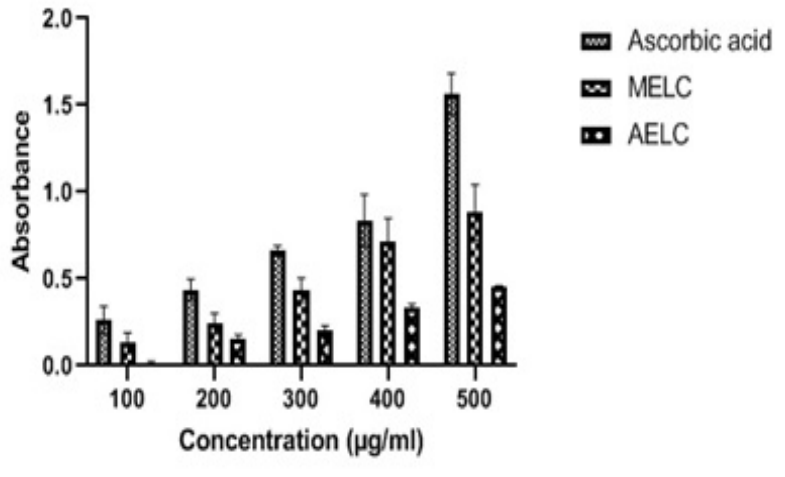

Figure 7: Phospho molybdenum assay of compared to that of standard ascorbic acid. Each value is expressed as mean \pm standard deviation $(n=3)$.

reported. However, antioxidant activities were found to possess in the bark extracts of Lannea coromandelica in this study.

\section{CONCLUSION}

Based on the results obtained, HPTLC fingerprinting was one of the possible approaches for medicinal plant identification and quality control to check the bioactive principle and standardization. However further work with marker compounds is necessary to perform quantitative estimation. This plant antioxidant potential also reveals their medicinal importance. The phytoconstituents responsible for antioxidant activity need to be explored and establish the specific mechanism of action for antioxidant activity.

\section{ACKNOWLEDGEMENT}

The authors express their gratitude to Principal and Management of Acharya and BM Reddy College of Pharmacy, for providing the support.

\section{CONFLICT OF INTEREST}

The authors declare no conflict of interest.

\section{ABBREVIATIONS}

DPPH: Free radical scavenging potential of 1,1 diphenyl 2 picryl hydrazyl; EALC: Ethyl acetate extracts of Lannea coromandelica; MELC: Methanol extracts of Lannea coromandelica; AELC: Aqueous extracts of extracts of Lannea coromandelica; GAE: Gallic acid equivalent; $\mathbf{Q E :}$ Quercetin equivalent; TFC: Total Flavanoid content; TPC: Total phenol content; FRAP: Ferric ion reducing antioxidant power assay; PM: Phosphomolybdenum assay.

\section{REFERENCES}

1. Nanfack P, Biapa N, Pieme C, Moor VA, Moukette B, Ngogang Y. The in vitro antisickling and antioxidant effects of aqueous extracts Zanthoxyllum heitzii on sickle cell disorder. BMC Complement Alternat Med. 2013;13(1):162.

2. Erkan N, Akgonen S, Ovat S, Goksel G, Ayranci E. Phenolic compounds profile and antioxidant activity of Dorystoechas hastata L. Boiss et Heldr. Food Research International. 2011;44(9):3013-20.

3. Soory M. Relevance of nutritional antioxidants in metabolic syndrome, ageing and cancer: Potential for therapeutic targeting. Infect Disorders Drug Targets. 2009;9(4):400-14.

4. Tapsell L, Hemphill I, Cobiac L, Patch CS, Sullivan DR, Fenech M, et al. Health benefits of herbs and spices: The past, the present, the future. Med J Aust. 2006; 185(S4):S1-24.

5. Noctor G, Foyer $\mathrm{CH}$. Ascorbate and glutathione: Keeping active oxygen under control. Annu Rev Plant Biol. 1998;49(1):249-79.

6. Schreck R, Baeuerle PA. A role for oxygen radicals as second messengers. Trends Cell Biol. 1991;1(2):39-42.

7. Kanchanlata S, Mustansir B, Yasar AK , Ganapathi B, Thankamani M. Antioxidants as precision weapons in war against cancer chemotherapy induced toxicity- Exploring the armoury of obscurity. Saudi Pharmaceutical Journal. 2018;26(2):177-90.

8. Ross R. The pathogenesis of atherosclerosis: A perspective for the 1990s. Nature. 1993;362 (6423):801-9.

9. Maron DJ. Flavonoids for reduction of atherosclerotic risk, Curr Atheroscler Rep. 2004;6:673-8.

10. Rivas AS, Guevara GR, Lopez VY, Rodríguez ME, Zanardo GM, et al. Oxidative stress caused by ozone exposure induces loss of brain repair in the hippocampus of adult rats. Toxicol Sci. 2010;113(1):187-97.

11. Rozanowska M, Jarvis-Evans J, Korytowski W, Boulton ME, Burke JM, Sarna T. Blue light-induced reactivity of retinal age pigment: In vitro generation of oxygen-reactive species. J Biol Chem. 1995;270(32):18825-30.

12. Cerutti PA. Prooxidant states and tumor promotion. Science. 1985;227(4685):375-81.

13. Finkel T, Holbrook NJ. Oxidants, oxidative stress and the biology of ageing. Nature. 2000;408(6809):239-47.

14. Yao LH, Jiang YM, Shi J, Tomas-Barberan FA, Datta N, et al. Flavonoids in food and their health benefits. Plant Foods Hum Nutr. 2004;59(3):113-22.

15. Dorman HJ, Kosar M, Kahlos K, Holm Y, Hiltunen R. Antioxidant properties and composition of aqueous extracts from Mentha species, hybrids varieties and cultivars. J Agric Food Chem. 2003;51(16):4563-9.

16. Tarhan L, Kayali HA, Urek RO. In vitro antioxidant properties of Cucurbita pepo L. male and female flowers extracts. Plant Foods Hum Nutr. 2007;62(2):49-51.

17. Tripathi AK, Verma RK, Gupta AK, Gupta MM, Khanuja SP. Quantitative determination of phyllanthin and hypophyllanthinin Phyllanthus species by high-performance thin layer chromatography. Phytochem Anal. 2006;17(6):394-7.

18. Nadkarnis KM. Indian Materia Medica. Popular Prakashan Pvt. Ltd., Mumbai. 1976;867-8.

19. Kirtikar KR and Basu BD. Indian Medicinal Plants. Lalit Mohan Basu. Allahabad. 1984;1:664-6.

20. Rahmatullah M, Azam MN, Khatun Z, Seraj S, Islam F, Rahman MA, et al. Medicinal plants used for treatment of diabetes by the Marakh sect of the Garo tribe living in Mymensingh district, Bangladesh. Afr J Tradit Complement Altern Med. 2012;9(3):380-5.

21. Zheng XL, Xing FW. Ethnobotanical study on medicinal plants around Mt. Yinggeling, Hainan Island, China. J Ethnopharmacol. 2009;124(2):197-210.

22. Mulaudzi RB, Ndhlala AR, Kulkarni MG, Staden J. Pharmacological properties and protein binding capacity of phenolic extracts of some venda medicinal plants used against cough and fever. J Ethnopharmacol. 2012;143(1):18593.

23. Kadir MF, Sayeed MSB, Mia MMK. Ethnopharmacological survey of medicinal plants used by traditional healers in Bangladesh for gastrointestinal disorders. J Ethnopharmacol. 2013;147(1):148-56.

24. Imam MZ, Moniruzzaman M. Antinociceptive effect of ethanol extract of leaves of Lannea coromandelica. J Ethnopharmacol. 2014;154(1):109-15. 
25. Weerapreeyakul N, Junhom C, Barusrux S, Thitimetharoch T. Induction of apoptosis in human hepatocellular carcinoma cells by extracts of Lannea coromandelica (Houtt.) Merr. and Diospyros castanea (Craib) Fletcher. Chin Med. 2016;11(19):01-10.

26. Egbe EO, Akumka DD, Adamu M, Mikail HG. Phytochemistry, antinociceptive and anti-inflammatory actvities of methanolic leaves extract of Lannea schimperi (Hoschst. Ex Rich) ENG. Recent Pat Biotechnol. 2016;9(2):145-50.

27. Kumar T, Jain V. Appraisal of total phenol, flavonoid contents and antioxidant potential of folkloric Lannea coromandelica using in vitro and in vivo assays. Scientifica. 2015;01-13.

28. Kaur R, Jaiswal ML, Jain V. Protective effect of Lannea coromandelica Houtt. Merrill. against three common pathogens. J Ayurveda Integr Med. 2013;4(4):224-8

29. Singh S, Singh G. Anti-inflammatory activity of Lannea coromandelica bark extract in rats. Phytother Res. 1994;8(5):311-3.

30. Singh S, Singh G. Hypotensive activity of Lannea coromandelica bark extract. Phytother Res. 1996;10(5):429-30.

31. Kumar V, Lemos M, Sharma M, Shriram V. Antioxidant and DNA damage protecting activities of Eulophia nuda Lindl. Free Radic Antiox. 2013;3(2):5560.

32. Alam B, Hossain S, Habib R, Rea J. Islam A. Antioxidant and analgesic activities of Lannea coromandelica Linn. bark extract. Int J Pharmacol. 2012;8(4):224-33.

33. Sameer W, Rajesh G, Swati J, Sushma S, Kalpana J. Lannea coromandelica attenuates glucagon and oxyntomodulin mediated cAAMP formation in HEK cells stably expressing human glucagon receptor. Journal of Herbal Medicine. 2015;5(3):153-7.

34. Imam MZ, Moniruzzaman M. Antinociceptive effect of ethanol extract of leaves of Lannea coromandelica. Journal of Ethnopharmacology. 2014;154(1):10915.

35. Xiao JY, Huo MS, Guang YC, Ming HJ, Jin YD. Chemical constituents from barks of Lannea coromandelica. Chinese Herbal Medicines. 2014;(1):65-9.

36. Badrul A, Kyoo RK, Seok HL, Sang HL. Lannea coromandelica (Houtt.) Merr. Induced heme oxygenase 1(HO-1) expression and reduces oxidative stress via the p38/c-Jun N-terminal kinase- nuclear factoe erythroid 2-related factor 2(p38/JNK-NRF2)-mediated antioxidant pathway. Int $\mathrm{J}$ Mol Sci. 2017;18(2):01-18.

37. Islam MT, Ito T, Sakasai M, Tahara S. Zoosporicidal activity of polyflavanoid tannin identified in Lannea coromandelica stem bark against phtopathogenic oomycete alphanomyces cochlioides. J Agric Food Chem. 2002;50(23):6697703.

38. Ajazuddin SS. Evaluation of physicochemical and phytochemical properties of Safoof-E-Sana, Unani polyherbal formulation. Pharmacognosy Res. 2010;2(5):318-22
39. Khandelwal KR. Techniques and Experiments, Practical Pharmacognosy. $17^{\text {th }}$ edition. Nirali Prakashan, Pune. 2007;149-56.

40. Kokate CK. Practical Pharmacognosy. Vallabh Prakashan, New Delhi. 1994;105-7.

41. Harborne JB. Phytochemical Methods. $3^{\text {rd }}$ edition. Chapman and Hall, London. 1998;60.

42. Wagner H, Baldt S, Zgainski EM. Plant drug analysis. Springer, Berlin. $2001 ; 85$.

43. Wolfe K, Wu X, Liu RH. Antioxidant activity of apple peels. J Agric Food Chem. 2003;51(3):609-14.

44. Olajire A, Azeez L. Total antioxidant activity, phenolic, flavonoid and ascorbic acid contents of Nigerian vegetables. African Journal of Food Science Technology. 2011;2(2):22-9.

45. Sonkawade SD, Naik GR. In vitro evaluation of antioxidant properties of sugarcane extracts rich in dietary nucleotides. Int J Adv Biol Res. 2016;5:24350 .

46. Tundis R, Menichini F, Bonesi M, Conforti F, Statti G, Meichini F, et al. Ant oxidant and hypoglycaemic activities and their relationship to phytochemicals in capsicum annum cultivars during fruit development. LWT-Food Science and Technology. 2013;53(1):370-7.

47. Prieto P, Pineda M, Aguilar M. Spectrophotometric quantitation of antioxidan capacity through the formation of a phosphomolybdenum complex: Specific application to the determination of vitamin E. Anal Biochem. 1999;269(2):33741.

48. Sharififar F, Dehghn NG, Mirtajaldini M. Major flavonoids with antioxidant activity from Teucrium polium L. Food Chemistry. 2009;112(4):885-8.

49. Zheng W, Wang SY. Antioxidant activity and phenolic compounds in selected herbs. J Agric Food Chem. 2001;49(11):5165-70.

50. Koleva II, Beek TAV, Linssen JPH, Aede DG, Evstatieva LN. Screening of plant extracts for antioxidant activity: A comparative study on three testing methods. Phytochem Anal. 2002;13(1):8-17.

51. Smith C, Halliwell B, Aruoma OI. Protection by albumin against the prooxidation action of phenolic dietary components. Food Chem Toxicol. 1992;30(6):483-9.

52. Saradha M, Paulsamy S. In vitro antioxidant activity and polyphenol estimation of methanolic extract of endangered medicinal tree species, Hildegardia populifolia (Roxb.) Schott and Endl. Int J Phytomed. 2012;4(3):362-8.

53. Heim KE, Tagliaferro AR, Bobilya DJ. Flavonoid antioxidants: Chemistry, metabolism and structure activity relationships. J Nutr Biochem. 2002;13(10):572-84.

54. Tekeshwar K, Vishal J. Appraisal of total phenol, flavanoid contents and antioxidant potential of folkloric Lannea coromandelica using in vitro and in vivo assays. Scientifica. 2015;13. Article ID 203679.

\section{PICTORIAL ABSTRACT}

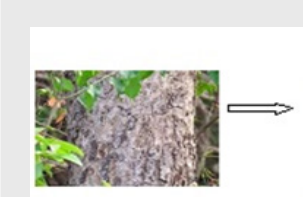

Procurement and authentication
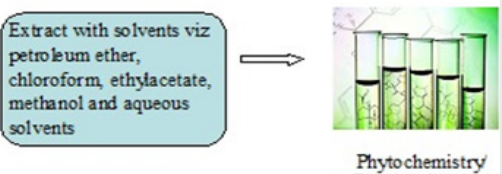
Phyto chemistry Parame ters $\prod$

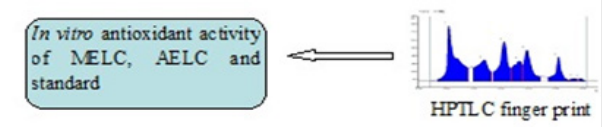

\section{About Authors}

Dr. Rajesh R, is an Associate Professor and HOD, Department of Pharmaceutical Analysis at Acharya \& BM Reddy College of Pharmacy, Bengaluru. He has 21 years of academic and research experience. $\mathrm{He}$ has wide experience in the area of chemistry of natural products and pharmaceutical analysis mainly in the area of phytochemistry, HPLC analytical and bioanalytical method development and validation. 


\section{SUMMARY}

Phytochemicals are a strong category of compounds that belong to secondary plant metabolites and comprise a number of chemical entities, including polyphenols, flavonoids, steroidal saponins, organosulfur compounds and vitamins. Oxidative stress results from increased ROS and/or reactive nitrogen species (RNS) resulted in autoimmune diseases such as cancer, inflammatory response, vascular disease and neurodegenerative disorder. Antioxidants have a role in neutralizing the excess of free radicals, protecting cells against their harmful effects and helping to prevent disease. While there are many synthetic antioxidants available and due to the risk of causing side effects they have limited use. Recent research activities have therefore been based on using natural plant antioxidants rather than synthetic antioxidants. HPTLC fingerprinting was one of the potential methods for the identification and quality control of medicinal plants in order to evaluate the bioactive principle and standardization. It was confirmed that the presence of poly phenol in the bark of Lannea coromandelica possesses antioxidant properties. These findings provide scientific evidence to prove its antioxidant ability and will be used to treat oxidative stress-related diseases in the near future with phytochemical based drugs.

Cite this article: Rajesh R. Phytochemical Screening, HPTLC Finger Print and in vitro Antioxidant Activity of Bark Extracts of Lannea coromandelica (Houtt.) Merr. Indian J of Pharmaceutical Education and Research. $2021 ; 55(2): 498-506$. 